\title{
Site-Specific Fluorescent Labeling of Antibodies and Diabodies Using SpyTag/SpyCatcher System for In Vivo Optical Imaging
}

\author{
Md. Kausar Alam, ${ }^{1}$ Ayman El-Sayed, ${ }^{1}$ Kris Barreto, ${ }^{1}$ Wendy Bernhard, ${ }^{1}$ \\ Humphrey Fonge, ${ }^{2}$ C. Ronald Geyer ${ }^{1}$ \\ ${ }^{1}$ Department of Pathology and Laboratory Medicine, College of Medicine, University of Saskatchewan, Saskatoon, SK, S7N 5E5, Canada \\ ${ }^{2}$ Department of Medical Imaging, College of Medicine, University of Saskatchewan, Saskatoon, SK, S7N 5E5, Canada
}

\begin{abstract}
Purpose: Construction of antibody-based, molecular-targeted optical imaging probes requires the labeling of an antibody with a fluorophore. The most common method for doing this involves non-specifically conjugating a fluorophore to an antibody, resulting in poorly defined, heterogeneous imaging probes that often have suboptimal in vivo behavior. We tested a new strategy to site-specific label antibody-based imaging probes using the SpyCatcher/SpyTag protein ligase system.

Procedures: We used the SpyCatcher/SpyTag protein ligase system to site specifically label nimotuzumab, an anti-EGFR antibody and an anti-HER3 diabody. To prevent the labeling from interfering with antigen binding, we introduced the SpyTag and SpyCatcher at the C-terminus of the antibody and diabody, respectively. Expression and binding properties of the C-terminal antibody-SpyTag and diabody-SpyCatcher fusions were similar to the antibody and diabody, indicating that the SpyTag and SpyCatcher fusions were well tolerated at this position. Sitespecific labeling of the antibody and diabody was performed in two steps. First, we labeled the SpyCatcher with IRDye800CW-Maleimide and the SpyTag with IRDye800CW-NHS. Second, we conjugated the IRDye800CW-SpyCatcher and the IRDye800CW-SpyTag to the antibody or diabody, respectively. We confirmed the affinity and specificity of the IRDye800CW-labeled imaging probes using biolayer interferometry and flow cytometry. We analyzed the in vivo biodistribution and tumor accumulation of the IRDye800CW-labeled nimotuzumab and antiHER3 diabody in nude mice bearing xenografts that express EGFR and HER3, respectively. Results: Expression and binding properties of the C-terminal antibody-SpyTag and diabodySpyCatcher fusions were similar to the antibody and diabody, indicating that the SpyTag and SpyCatcher fusions were well tolerated at this position. We confirmed the affinity and specificity of the IRDye800CW-labeled imaging probes using biolayer interferometry and flow cytometry. We analyzed the in vivo biodistribution and tumor accumulation of the IRDye800CW-labeled nimotuzumab and anti-HER3 diabody in nude mice bearing xenografts that express EGFR and HER3, respectively. Site-specifically IRDye800CW-labeled imaging probes bound to their
\end{abstract}

Md. Kausar Alam and Ayman El-Sayed contributed equally to this work. Electronic supplementary material The online version of this article (https:// doi.org/10.1007/s11307-018-1222-y) contains supplementary material, which is available to authorized users.

Correspondence to: Humphrey Fonge; e-mail: humphrey.fonge@usask.ca,

C. Geyer; e-mail: ron.geyer@usask.ca 
immobilized targets, cells expressing these targets, and selectively accumulated in xenografts. Conclusions: These results highlight the ease and utility of using the modular SpyTag/ SpyCatcher protein ligase system for site-specific fluorescent labeling of protein-based imaging probes. Imaging probes labeled in this manner will be useful for optical imaging applications such as image-guided surgery and have broad application for other imaging modalities.

Key words: Site-specific labeling, Near infrared imaging, Nimotuzumab, EGFR, Antibody, Diabody, HER3, SpyTag/SpyCatcher

\section{Introduction}

Non-invasive optical imaging is an emerging approach that aids clinicians in many aspects of cancer diagnosis and treatment [1-3]. Antibody-based, molecular targeted imaging (MTI) probes are being developed for optical imaging to allow visualization of disease-specific markers. One challenge in constructing MTI probes is conjugating fluorophores to antibodies. Fluorophores are most commonly conjugated to antibodies in a non-specific manner, which can result in decreased antigen-binding affinity and poor pharmacological properties [4-7]. To overcome this problem, methods have been developed to label antibodies at specific locations. Site-specific conjugation can be achieved by labeling cysteines or by incorporating peptide tags or modified amino acids [6-14]. While promising, each of these methodologies has limitations. For example, labeling of cysteines requires the reduction of natural disulfide bonds or the introduction of cysteine resides via genetic engineering; processes that require significant optimization [6, 7]. Peptide tags fused to biologic imaging probes can be used for site-specific modifications; however, they often have low labeling efficiencies, require expensive reagents, or result in large fluorophore-protein probes. Peptide tag-based labeling allows the fluorophore to be attached at a specific location on the imaging probe, with minimal off-site labeling [6, 7]. Examples of peptide tag-based labeling methods include SNAP/CLIP $\left(\mathrm{O}^{6}\right.$ alkylguanine-DNA alkyltransferase) [8, 9], Halo-tag [10], Sfp phosphopantetheinyl transferase (CoA) [11], Sortase A [12], and Avi biotin ligase recognition peptide [7]. The fusion of peptide tags increases the size $(18-33 \mathrm{kDa})$ of the imaging probe and can sterically hinder antigen binding [7]. However, site-specific labeling using peptide tags results in MTI probes that are more homogenous [9] compared to random approaches [7].

We tested the effectiveness of using the SpyCatcher/ SpyTag protein ligase system to site specifically label MTI probes for in vivo optical imaging. This system is based on the collagen adhesin domain (CnaB2) of the fibronectin binding protein $(\mathrm{FbaB})$ from $S$. pyogenes. $\mathrm{CnaB} 2$ contains an intramolecular isopeptide covalent bond formed between aspartate and lysine. CnaB2 is split into two fragments to produce a SpyTag (13 amino acids) and SpyCatcher (138 amino acids), which can interact and form the isopeptide bond $[15,16]$. The SpyTag and SpyCatcher can be fused to either the C- or N-termini of proteins [15-17]. SpyTag and SpyCatcher protein fusions can form a conjugated product under a variety of conditions $[15,16]$. This system has been used to construct antibody-like proteins [17], develop VLPvaccines [18], construct a synthetic vaccine [19], conjugate a dye to an antibody [20], target gene delivery [21], and label membrane proteins [22].

We tested the ability of the SpyTag/SpyCatcher system to site specifically label two different-sized antibody-based MTI probes in two orientations. We constructed a Cterminus antibody-SpyTag fusion and ligated it to a fluorophore-labeled SpyCatcher. We labeled a diabody in the reverse orientation by constructing a C-terminus diabody-SpyCatcher fusion and ligated it to a fluorophorelabeled SpyTag.

We used the SpyCatcher/SpyTag system to site specifically label the anti-human epidermal growth factor receptor (EGFR) antibody, nimotuzumab, and the antihuman epidermal growth factor receptor 3 (HER3) diabody to evaluate their potential as probes for in vivo optical imaging. Overexpression of EGFR in tumors correlates with increased metastasis, decreased survival, and poor prognosis [23]. Nimotuzumab has recently been shown to be promising probe for MTI [24]. HER3 plays an integral role in HER2-amplified breast cancer through its ability to dimerize with HER2, contributing to tumorigenesis and correlating with poorer clinical outcomes [25] and trastuzumab resistance [26].

We demonstrated site-specific labeling of nimotuzumab and an anti-HER3 diabody using the SpyCatcher/SpyTag system for in vivo cancer imaging. We generated nimotuzumab-SpyTag and anti-HER3 diabody-SpyCatcher fusions and ligated them to fluorescently labeled SpyCatcher and SpyTag, respectively. We confirmed the ligation efficiency and in vitro binding affinity and specificity of the fluorescent-labeled nimotuzumab and anti-HER diabody. We analyzed the in vivo biodistribution and tumor accumulation properties of these EGFR and HER3 fluorescent imaging probes in mice bearing tumor xenografts expressing EGFR or HER3. 


\section{Materials and Methods}

\section{Cloning}

Expression plasmids were cloned using standard PCR methods and Gibson assembly [27]. To generate pFUSEssCHIg-Nimotuzumab-hG1-SpyTag and pFUSEss-CHIgMBP-hG1-SpyTag plasmids, we first introduced SpyTag into the pFUSEss-CHIg-hG1 plasmid (Invivogen) at the Cterminus of the Fc domain to generate pFUSEss-CHIg-hG1SpyTag plasmid. Nimotuzumab and anti-MBP VH domains were then introduced at the $\mathrm{N}$-terminus of $\mathrm{CH} 1$ of the pFUSEss-CHIg-hG1-SpyTag plasmid to generate pFUSEssCHIg-Nimotuzumab-hG1-SpyTag (see Electronic Supplementary Material (ESM): SEQ:01) and pFUSEss-CHIgAnti-MBP-hG1-SpyTag (see ESM SEQ:02) plasmids, respectively. To generate pFUSEss-CLIg-Nimotuzumab-hG1 and pFUSEss-CLIg-Anti-MBP-hG1 plasmids, nimotuzumab and anti-MBP VL domain were introduced at the N-terminus of CL of pFUSEss-CLIg-hG1-hk plasmid (Invivogen), respectively.

We used the previously reported pCW-SpyCatcher-His ${ }_{6}$ [17] to clone the anti-HER3-diabody and anti-MBP-diabody. To generate $\mathrm{pCW}$-anti-HER3-diabody-SpyCatcher-His ${ }_{6}$ (see ESM SEQ:03) and pCW-anti-MBP-diabody-SpyCatcher$\mathrm{His}_{6}$ (see ESM SEQ:04) plasmids, the anti-HER3-diabody and anti-MBP-diabody were PCR amplified from $\mathrm{pCW}$-antiHER3-Fab and pCW-anti-MBP-Fab plasmids [28], respectively, using overlap extension primers TGS157 and KA3R primers [17]. The PCR product was cloned into Sac1/Xholdigested pCW-SpyCatcher-His 6 plasmid using Gibson assembly.

\section{Expression and Purification of Antibodies}

Nimotuzumab-SpyTag and anti-MBP-SpyTag were expressed using the Gibco ${ }^{\mathrm{TM}}$ Expi293 ${ }^{\mathrm{TM}}$ Expression System (Life Technologies, catalog number A14635), according to the manufacturer's protocol. Briefly, 1 day before transfection, Expi293F cells were diluted to $2 \times 10^{6}$ cells $/ \mathrm{ml}$ in Expi293 Expression Medium (Life Technologies). On the day of transfection, $30 \mu \mathrm{g}$ of plasmid DNA (1:1 ratio) was complexed with $80 \mu \mathrm{L}$ ExpiFectamine ${ }^{\mathrm{TM}} 293$ reagent. The complexed DNA was then transferred to $7.5 \times 10^{7}$ cells (final cell density of $2.5 \times 10^{6}$ cells $/ \mathrm{ml}$ ). The next day, enhancers 1 and 2 were added to the media to bring the final volume up to $30 \mathrm{ml}$. Cells were cultured for 6-7 days. Cells were spun down, and supernatant was collected and filtered through a $0.45-\mu \mathrm{m}$-membrane filter (Minisart, Sartorius Stedim). Protein A binding buffer (Sodium Phosphate $20 \mathrm{mM}, 0.15 \mathrm{M} \mathrm{NaCl}, \mathrm{pH}$ 7.2) was added to the supernatant, and the antibody-SpyTag was purified by GE Healthcare AKTA FPLC system using HiTrap MabSelect column (GE healthcare). The antibody-SpyTag was eluted using $\operatorname{IgG}$ elution buffer (Fisher Scientific) and neutralized with Neutralization Buffer (1 M Tris- $\mathrm{HCl} \mathrm{pH}$ 9.0). Antibody-
SpyTag was dialyzed overnight with phosphate-buffered saline (PBS) and concentrated using a $30 \mathrm{~K}$ MWCO filter (Millipore). Fragments were filter sterilized and stored at $80{ }^{\circ} \mathrm{C}$.

\section{Expression and Purification of Diabody- SpyCatcher Fusions}

Anti-HER3 diabody-SpyCatcher and anti-MBP diabodySpyCatcher expression plasmids have a pelB sequence for mediating its secretion into the periplasmic space of E. coli. Plasmids were electroporated into RosettaTM (DE3) competent $E$. coli cells (Novagen) and cultured on LB agar plates containing carbenicillian $(100 \mu \mathrm{g} / \mathrm{m})$ and chloramphenicol (34 $\mu \mathrm{g} / \mathrm{ml}$ ). Single colonies were picked and cultured overnight in Instant TB media (Novagen) for $20 \mathrm{~h}$ at $30{ }^{\circ} \mathrm{C}$ with shaking (250 RPM). Diabody-SpyCatcher fusions were purified with the AKTA FPLC system (GE Healthcare) using HiTrap Protein L column (GE healthcare) as described previously [17]. Briefly, the cell pellet was collected by centrifugation and re-suspended in Protein L binding buffer (sodium phosphate $20 \mathrm{mM}, 0.15 \mathrm{M} \mathrm{NaCl}, \mathrm{pH} \mathrm{8.0)}$ ). The cell pellet was lysed using a Cell Disruptor (Constant System LTD. USA) set at $35 \mathrm{Kpsi}$. The cell lysis solution was centrifuged at $12,000 \times \mathrm{g}$ for $20 \mathrm{~min}$. The supernatant was collected and filtered through a $0.45-\mu \mathrm{m}$-membrane filter (Minisart, Sartorius Stedim) and loaded onto a HiTrap Protein L column using Akta Prime system (GE Healthcare). Diabodies were eluted using $\operatorname{IgG}$ elution buffer (Fisher Scientific) and neutralized with neutralization buffer (1 M Tris-HCl pH 9.0). Purified diabodies were dialyzed overnight in PBS and concentrated using $10 \mathrm{~K}$ MWCO filter. Diabodies were filter sterilized and stored at $-80^{\circ} \mathrm{C}$.

\section{IRDye800CW Labeling of SpyTag and SpyCatcher}

The SpyTag peptide (AHIVMVDAYKPTK) was purchased from Genescript. IRDye800CW-NHS ester (LI-COR Biosciences Co., Lincoln, NE) was used to label the SpyTag. $1 \mathrm{mg}$ of SpyTag in $1 \mathrm{ml}$ phosphate-buffered saline (PBS, $\mathrm{pH}$ 7.4) was labeled with 3 -fold molar excess of IRDye $800 \mathrm{CW}-\mathrm{NHS}$ by slowly rotating the mixture for $2 \mathrm{~h}$ at room temperature protected from light followed by rotating overnight at $4{ }^{\circ} \mathrm{C}$. The reaction was quenched with molar excess of $1 \mathrm{M}$ Tris. The labeled SpyTag was stored at $-20{ }^{\circ} \mathrm{C}$.

The SpyCatcher with a cysteine at the N-terminus was purchased from Kerafast (\#EOX004). IRDye800CWMaleimide (LI-COR Biosciences Co., Lincoln, NE, USA) and used to label the cysteine-SpyCatcher. SpyCatcher $(1 \mathrm{mg}$ ) in $1 \mathrm{ml}$ phosphate-buffered saline (PBS, pH 7.4) was reduced by adding 70-fold molar excess of Tris(2Carboxyethyl)Phosphine hydrochloride (TCEP) and incubated overnight at $4{ }^{\circ} \mathrm{C}$ with shaking. Excess TCEP was removed using Zeba Spin Desalting Columns, 7 K MWCO 
(Thermo Scientific, catalog number 89892). The reduced SpyCatcher was labeled with 10 -fold molar excess of IRDye $800 \mathrm{CW}-$ Maleimide by rotating for $2 \mathrm{~h}$ at room temperature protected from light followed by rotating overnight at $4{ }^{\circ} \mathrm{C}$. Excess dye was removed by passing the solution through $5 \mathrm{ml}$ Zeba Spin Desalting Columns, $7 \mathrm{~K}$ MWCO. The labeled SpyCatcher was stored at $-80^{\circ} \mathrm{C}$.

\section{Ligation of Antibody-SpyTag with SpyCatcher- IRDye800CW and Diabody-Catcher with SpyTag- IRDye800CW}

Nimotuzumab-SpyTag and anti-MBP-SpyTag $(10 \mu \mathrm{M})$ were ligated to SpyCatcher-IRDye800CW $(30 \mu \mathrm{M})$ for $3 \mathrm{~h}$ at room temperature in the presence of phosphate-citrate buffer, $\mathrm{pH} \mathrm{7,} \mathrm{as} \mathrm{described} \mathrm{by} \mathrm{Alam} \mathrm{et} \mathrm{al.} \mathrm{[17]} \mathrm{and} \mathrm{Zakeri}$ et al. [15]. Ligated products were named to reflect orientation the orientation of the SpyTag and SpyCatcher. For example, antibody-SpyCatcher reacted with SpyTagIRDye $800 \mathrm{CW}$ was labeled antibody-SpyCatcher/SpyTagIRDy800CW. Nimotuzumab-SpyTag/ SpyCatcherIRDye $800 \mathrm{CW}$ and anti-MBP-SpyTag/SpyCatcher IRDye $800 \mathrm{CW}$ were purified using Protein A chromatography to remove unligated SpyCatcher-IRDye800CW. AntiHER3 diabody-SpyCatcher and anti-MBP diabodySpyCatcher $(10 \mu \mathrm{M})$ were ligated to SpyTag-IRDye800CW $(30 \mu \mathrm{M})$ using the same protocol described previously [17]. Diabody-SpyCatcher/SpyTag-IRDye800CW products were filtered through $10 \mathrm{kDa}$ MWCO concentrator (Millipore). The filtration was repeated four times with PBS to remove unligated SpyTag-IRDye800CW.

Antibody-SpyTag/SpyCatcher-IRDye $800 \mathrm{CW}$ and diabody-SpyCatcher/SpyTag-IRDye800CW were filter sterilized using Millipore Ultrafree MC Centrifugal Filter Device. The concentration was measured using the formula: Protein Conc $(\mathrm{mg} / \mathrm{ml})=(\mathrm{A} 280-(0.030 \mathrm{~A} 780)) / \varepsilon$ Protein $\times$ MWprotein $\times$ dilution factor. 0.03 is a correction factor for the absorbance of the IRDye $800 \mathrm{CW}$ at $280 \mathrm{~nm}$ (equal to $3.0 \%$ of its absorbance at $780 \mathrm{~nm}$ ). $\varepsilon_{\text {Protein }}$ is the molar extinction coefficient for protein. $\mathrm{MW}_{\text {protein }}$ is the molecular weight of the protein. Dilution factor is the dilution of the labeled protein prior to measurement by spectrophotometer. The number of IRDye $800 \mathrm{CW}$ molecules on the antibody or diabody was calculated using the following formula: IRDye $800 \mathrm{CW} /$ protein $=\left(A_{789} / \varepsilon_{\mathrm{IR}}\right) /\left(A_{280}-\left(0.03 \times A_{778}\right) /\right.$ $\left.\varepsilon_{\text {Protein }}\right)$, where $\varepsilon_{\mathrm{IR}}$ is the molar extinction coefficient of IRDye $800 \mathrm{CW}$ and $\varepsilon_{\text {Protein }}$ is the molar extinction coefficients of the antibody or diabody.

\section{SDS-PAGE Analysis}

Purified IRDye800CW labeled and unlabeled antibodies and diabodies were resolved under reducing or non-reducing conditions using a precast BioRad 4-15\% gel (BioRad, catalog number 56-1084) with a BioRad PowerPac ${ }^{\mathrm{TM}}$ Cell.
Gels were stained with coomassie blue. After destaining, protein bands were visualized by BioRad GelDoc $\mathrm{XR}^{+}$ system. Unstained SDS-PAGE gels were scanned using the Odyssey Infrared Imaging system (LI-COR Bioscience) and images processed using the Odyssey 3.0.16 application software (LI-COR Bioscience).

\section{Electrophoresis-Based Analysis on Agilent 2100 Bioanalyzer}

The molecular weight (MW) and purity of antibodies and diabodies were measured using High Sensitivity Protein 250 Kit (Agilent, catalog number 5067-1575), according to the manufacturer's protocol. Briefly, antibodies and diabodies $(1 \mathrm{mg} / \mathrm{ml})$ were labeled with fluorescent dye and analyzed using the 2100 Bioanalyzer System (Agilent). The molecular weight and peak areas were calculated using 2100 Expert software (Agilent).

\section{Biolayer Interferometry}

Kinetic analyses were performed using a ForteBio OctetRed 384 instrument, according to the manufacturer's protocols. SpyCatcher/SpyTag Nimotuzumab constructs were immobilized to anti-human IgG Fc-capture sensors (ForteBio) and its interaction with the recombinant hEGFR (R\&D system) analyte was measured. For the SpyCatcher/ SpyTag anti-HER3 diabody, recombinant Fc-hHER3 (R\&D system) was immobilized to anti-human IgG Fc-capture sensors (ForteBio), and its interaction with the diabody analyte was measured. The unlabeled anti-HER3 diabody was immobilized to amine-reactive generation 2 (ARG2) sensors (ForteBio), and its interaction with the recombinant Fc-hHER3 (R\&D system) analyte was measured. Antibodies and fragments were immobilized to sensors by dipping the sensor in a 384-well tilted-bottom plate, containing $50 \mu \mathrm{l}$ of $10-12 \mu \mathrm{g} / \mathrm{ml}$ of antibody or fragment. Association rates $\left(k_{\mathrm{on}}\right)$ were monitored for 2-5 min, and dissociation rates $\left(k_{\text {off }}\right)$ were monitored for $10 \mathrm{~min}$. Binding reactions were performed at $30{ }^{\circ} \mathrm{C}$ in PBS. Data was collected with Octet Data Acquisition version 8.1 (ForteBio) and globally fit to 1:1 binding model using Octet Data Analysis version 7.1 (ForteBio).

\section{Cell Lines}

The human squamous carcinoma A431 cell line overexpressing EGFR was obtained from ATCC (Rockville, MD, USA). The human head and neck squamous cell carcinoma FaDu cell line over-expressing HER3 was obtained from ATCC (Rockville, MD, USA). Cells were propagated by serial passage in RPMI and MEM/EBSS medium, respectively, supplemented with $10 \%$ fetal bovine 
serum (Biochrom) at $37{ }^{\circ} \mathrm{C}$ in a humidified atmosphere of $5 \% \mathrm{CO}_{2}$.

\section{Flow Cytometry}

Binding of antibody-SpyTag/SpyCatcher-IRDye $800 \mathrm{CW}$ to A431 cells and diabody-SpyCatcher/SpyTag-IRDye800CW to $\mathrm{FaDu}$ cells were determined using flow cytometry. For flow cytometric analysis, $2 \times 10^{5}$ cells/tube were incubated with 50 pmoles of IRDye $800 \mathrm{CW}$ labeled antibodies or diabodies at room temperature, protected from light, for 60 min, followed by three washes with PBS, pH 7.4. Fluorescent emission of cells was monitored using a Gallios flow cytometer (Beckman Coulter, Inc.) at $640 \mathrm{~nm}$ excitation with emission filter set up at $745-825 \mathrm{~nm}$. Flow cytometry data were analyzed using Kaluza (Beckman Coulter, Inc.).

\section{In Vivo Animal Imaging}

Animals used in the imaging experiments were cared for and maintained under the supervision and guidelines of the University of Saskatchewan Animal Care Committee. Female CD-1 nude mice were obtained from Charles River Canada (St-Constant, Quebec, Canada) at 4 weeks of age and housed in a $12 \mathrm{~h} \mathrm{light/dark}$ cycle in a temperature and humidity controlled vivarium. Animals had ad libitum access to mouse diet (Lab Diet, St. Louis, MO, USA) and water. After 1 week of acclimatization, mice were subcutaneously injected with a suspension of $1 \times 10^{7}$ A431 cells or $\mathrm{FaDu}$ cells in $100 \mu \mathrm{l}$ of a $1: 1$ mixture of serum-free MEM/EBSS medium (HyClone Laboratories, Logan, UT, USA) and Matrigel matrix basement membrane (Discovery Laboware, Inc. Bedford, MA, USA) at the hind limb of each mouse. Tumor growth was followed with external caliper measurements. Tumor volume was calculated using the following formula: tumor volume $=$ length $\times$ width $^{2} \times 0.5$ [29]. Tail vein injections of 0.5 nmole of antibody-SpyTag/ SpyCatcher-IRDye800CW for A431 xenografts and diabody-SpyCatcher/SpyTag-IRDye800CW for FaDu xenografts were injected intravenously when xenografts measured 150-300 $\mathrm{mm}^{3}$. Mice were anesthetized with $2.5 \%$ isoflurane and imaged at different time points using the Pearl Impulse Imager (LI-COR) with excitation/emission settings of $785 / 820 \mathrm{~nm}$. The fluorescence signal was overlaid with the white light image captured by a CCD camera, and images were analyzed using Image Studio Software (version 3.1). Regions of interest (ROI) for xenografts, liver, kidneys, and background were selected from equivalent-sized areas containing the same number of pixels. Three ROIs were quantified per organ for each mouse and three mice were imaged per antibody or diabody. Antibody and diabody raised against MBP served as non-specific control in imaging experiments.

\section{Results}

\section{Purification and Analysis of Nimotuzumab- SpyTag Fusion}

To minimize the effect of the fusion protein on antigen binding, we genetically fused the SpyTag and SpyCatcher to the heavy chain C-terminus of nimotuzumab. Expression yields of nimotuzumab-SpyTag were $5 \pm 2 \mathrm{mg} / \mathrm{L}$ from Expi293F cells in culture, whereas yields of nimotuzumabSpyCatcher were $1.0 \pm 0.3 \mathrm{mg} / \mathrm{L}$. Based on the higher expression levels of nimotuzumab-SpyTag, we used this fusion for ligation experiments. We also expressed and purified an anti-MBP antibody [30] as a SpyTag fusion (anti-MBP-SpyTag) for use as a control in imaging experiments.

We characterized the size, purity, and antigen-binding of nimotuzumab-SpyTag fusion (Fig. 1a). Under non-reducing conditions, nimotuzumab-SpyTag migrated at $151 \mathrm{kDa}$ and was $96 \%$ pure (Fig. 1a). The dissociation constant $\left(K_{\mathrm{D}}\right)$ of nimotuzumab-SpyTag for EGFR was $17.7 \mathrm{nM}$ (Table 1; Fig. 1a), which was not significantly different $(p>0.05)$ from the previously reported $K_{\mathrm{D}}$ of nimotuzumab for EGFR $(22.3 \pm 2.3 \mathrm{nM})[31]$.

\section{Site-Specific Labeling of Nimotuzumab-SpyTag with IRDye800CW-SpyCatcher}

We labeled nimotuzumab-SpyTag with fluorescent SpyCatcher using the scheme in Fig. 1b. We labeled the only cysteine on SpyCatcher with the near infrared fluorescent dye (IRDye800CW-Maleimide). The SpyCatcherIRDye $800 \mathrm{CW}$ had two bands (15 and $30 \mathrm{kDa}$ ) when resolved by non-reducing SDS-PAGE, representing the monomer and dimer, respectively (Fig. 1c). The labeling ratio of SpyCatcher was $0.56 \pm 0.03$. The nimotuzumabSpyTag was ligated to SpyCatcher-IRDye800CW at 1:3 M ratio to produce nimotuzumab labeled with two SpyCatcherIRDye800CW molecules. When nimotuzumab-SpyTag or anti-MBP-SpyTag were ligated to SpyCatcherIRDye $800 \mathrm{CW}$ their molecular weight (MW) increased slightly and they were fluorescent (Fig. 1c). We purified the IRDye800CW-labeled antibodies using Protein A chromatography and analyzed their MW and purity. IRDye $800 \mathrm{CW}$-labeled nimotuzumab had a MW of $181 \mathrm{kDa}$, which was $30 \mathrm{kDa}$ heavier than the nimotuzumab-SpyTag, indicating that two IRDye $800 \mathrm{CW}$ SpyCatchers were ligated to nimotuzumab-SpyTag (Fig. 1d). We determined the labeling ratio of IRDye $800 \mathrm{CW}$-labeled nimotuzumab and anti-MBP to be 1.03 and 1.07 , respectively (Table 2). The labeling ratio of nimotuzumab-SpyTag and anti-MBP-SpyTag were less than 2 because the labeling 


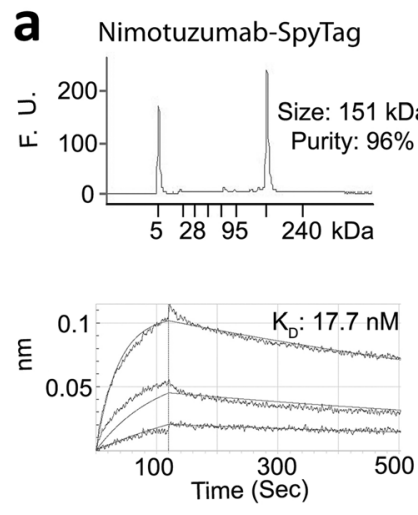

b

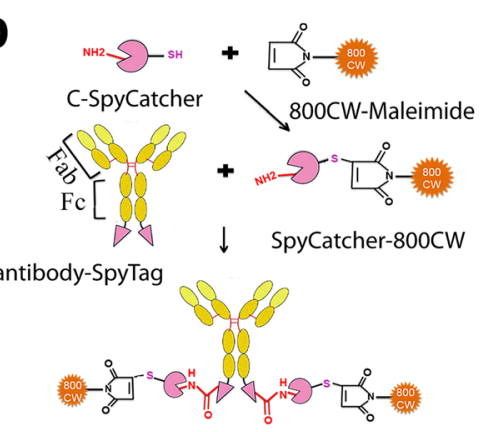

antibody-SpyTag/SpyCatcher-800CW
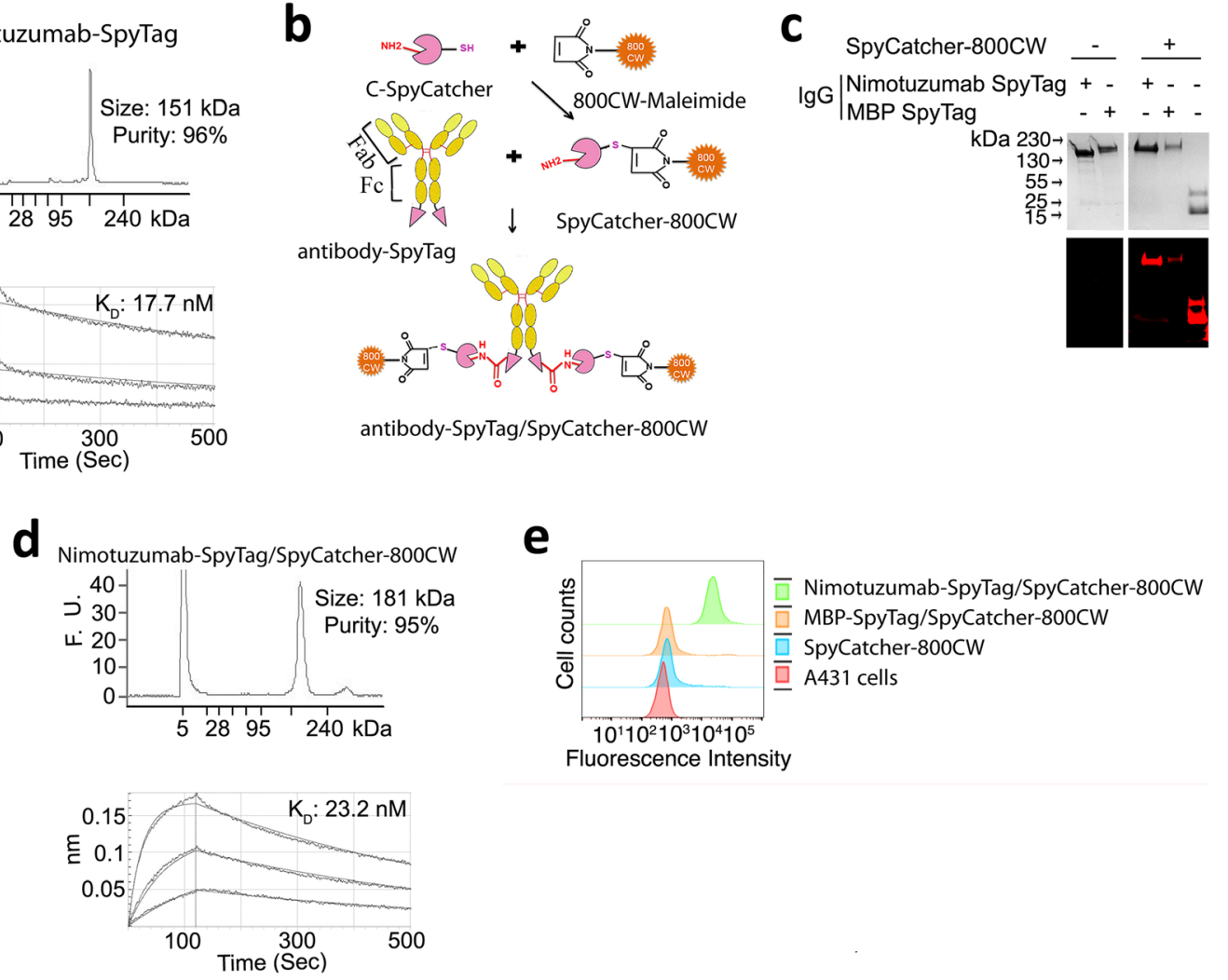

e

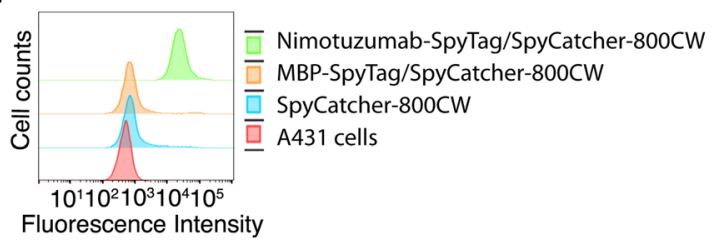

Fig. 1. Purification, site-specific labeling, and in vitro characterization of SpyTag-fused antibody. a Bio-analyzer electropherograms (top) and biolayer interferometry kinetic analysis (bottom) of nimotuzumab-SpyTag showing the purity, molecular weight $(\mathrm{MW})$, and dissociation constant $\left(K_{\mathrm{D}}\right)$ before labeling. Bioanalyzer was performed under non-reducing conditions. $5 \mathrm{kDa}$ peak is an internal standard used to align electropherograms. $K_{\mathrm{D}}$ was determined using biolayer interferometry with surface-immobilized EGFR. b Site-specific labeling of antibody-SpyTag with IRDye800CW-Maleimidelabeled SpyCatcher. First, C-SpyCatcher was conjugated with IRDye800CW-Maleimide. Then IRDye800CW-Maleimide-labeled SpyCatcher was conjugated with SpyTag-fused antibody for site-specific labeling. c Analysis of Protein A purified antibodySpyTag using non-reducing SDS-PAGE (top). LI-COR-Odyssey infrared image of the same gel (bottom) showing only SpyCatcher-IRDye800CW-labeled antibody-SpyTag. SpyTag was introduced at the C-terminus of Fc region of antibody. d Bioanalyzer electropherograms (top, $5 \mathrm{kDa}$ peak is an internal standard used to align electropherograms) and biolayer interferometry kinetic analysis (bottom) of nimotuzumab-SpyTag showing the purity, molecular weight (MW), and $K_{\mathrm{D}}$ after sitespecific labeling. e Flow cytometry analysis of nimotuzumab-SpyTag/SpyCatcher-800CW to A431 cells.

ratio of the SpyCatcher was 0.56. Thus, SpyTags on nimotuzumab and anti-MBP antibody were ligated with both IRDye $800 \mathrm{CW}$-labeled and unlabeled SpyCatcher. The resulting IRDye $800 \mathrm{CW}$-labeled nimotuzumab was $95 \%$ pure (Fig. 1d), bound recombinant EGFR with a $K_{\mathrm{D}}$ of $23.2 \mathrm{nM}$ (Table 1; Fig. 1d), and bound to an EGFR-positive

Table 1. Binding affinity of nimotuzumab IgG and anti-HER3 diabody fragments against recombinant EGFR and HER3 receptors respectively as measured by biolayer interferometry. Values presented as value $\pm \mathrm{SD}$

\begin{tabular}{llll}
\hline Nimotuzumab & \multicolumn{2}{l}{ EGFR receptor } & \\
\cline { 2 - 4 } & $k_{\text {on }}\left(\mathrm{M}^{-1} \mathrm{~s}^{-1}\right)$ & $k_{\text {off }}\left(\mathrm{s}^{-1}\right)$ & $K_{\mathrm{D}}(M)$ \\
\hline SpyTag & $5.31 \mathrm{E}+04 \pm 1.00 \mathrm{E}+03$ & $9.38 \mathrm{E}-04 \pm 1.12 \mathrm{E}-05$ & $1.77 \mathrm{E}-08 \pm 3.95 \mathrm{E}-10$ \\
SpyTag/SpyCatcher-IRDye800CW & $7.82 \mathrm{E}+04 \pm 7.35 \mathrm{E}+02$ & $1.82 \mathrm{E}-03 \pm 6.71 \mathrm{E}-06$ & $2.32 \mathrm{E}-08 \pm 2.35 \mathrm{E}-10$ \\
Anti-HER3 diabody & HER3 receptor & & \\
Unlabeled & $2.17 \mathrm{E}+04 \pm 2.19 \mathrm{E}+02$ & $2.43 \mathrm{E}-08 \pm 4.65 \mathrm{E}-10$ \\
SpyCatcher & $1.82 \mathrm{E}+04 \pm 1.65+02$ & $2.42 \mathrm{E}-08 \pm 6.6 \mathrm{E}-10$ \\
SpyCatcher/SpyTag-IRDye800CW & $2.50 \mathrm{E}+05 \pm 3.72 \mathrm{E}+02$ & $4.41 \mathrm{E}-04 \pm 1.14 \mathrm{E}-05$ & $3.46 \mathrm{E}-08 \pm 9.21 \mathrm{E}-10$ \\
\hline
\end{tabular}


Table 2. After labeling quality control; molecular weight, purity, and labeling efficiencies of IgG conjugates and antibody fragments. As observed by running on Agilent 2100 Bioanalyzer system under non-reducing (IgG) and reducing (diabody) conditions using the Agilent Protein 250 kit

\begin{tabular}{|c|c|c|c|c|c|}
\hline Construct & Label & MW calc $(\mathrm{kDa})$ & MW obs (kDa) & Purity (\%) & Labeling ratio \\
\hline Nimotuzumab-SpyTag & SpyCatcher-IRDye800CW & 175.4 & 181 & $95 \%$ & 1.03 \\
\hline Anti-MBP-SpyTag & SpyCatcher-IRDye $800 \mathrm{CW}$ & 181 & 186.8 & $100 \%$ & 1.07 \\
\hline Anti-HER3-diabody-SpyCatcher & SpyTag-IRDye800CW & 40.5 & 45.5 & $88 \%$ & 2.76 \\
\hline Anti-MBP-diabody-SpyCatcher & SpyTag-IRDye800CW & 40.6 & 45.8 & $76 \%$ & 2.44 \\
\hline
\end{tabular}

cell line, A431 (Fig. 1e). The IRDye $800 \mathrm{CW}$-labeled antiMBP was $100 \%$ pure, had a MW of $187 \mathrm{kDa}$ (Table 2), and did not bind A431 cells (Fig. 1e).

\section{Near Infrared Fluorescent Imaging of Nimotuzumab-SpyTag/SpyCatcher-IRDye800CW}

The in vivo biodistribution of nimotuzumab-SpyTag/ SpyCatcher-IRDye $800 \mathrm{CW}$ was evaluated by injecting 0.5 nmole in mice bearing subcutaneous A431 xenografts on their right hind limb. Anti-MBP-SpyTag/SpyCatcherIRDye $800 \mathrm{CW}$ was used as control to confirm that uptake of nimotuzumab-SpyTag/SpyCatcher-IRDye $800 \mathrm{CW}$ was selective. Mice were imaged at 1, 2, 3, 4, 6, 24, 48, 72, and 168 post-injection (hpi), and the fluorescent intensity in the xenograft and kidneys were quantified in dorsal images and the liver in ventral images. We used the A431 cell line as it has high levels of EGFR expression [31]. Nimotuzumab-SpyTag/SpyCatcher-IRDye800CW accumulated in A431 xenografts, whereas there was minimal accumulation for the anti-MBP-SpyTag/SpyCatcherIRDye $800 \mathrm{CW}$ (Fig. 2). Fluorescence intensities of nimotuzumab-SpyTag/SpyCatcher-IRDye $800 \mathrm{CW}$-labeled xenografts were significantly higher than the non-specific xenograft accumulation of anti-MBP-SpyTag/SpyCatcherIRDye $800 \mathrm{CW}$ at all time points measured $(p$ value $<0.01$ ) (see ESM Fig. S1). By 72 hpi the nimotuzumab-SpyTag/ SpyCatcher-IRDye800CW fluorescence intensity was higher in the xenograft than elsewhere in the mouse. Fluorescence persisted in A431 xenografts up to $168 \mathrm{hpi}$ (Fig. 2c). Hepatic clearance has been reported as the preferred route for antibodies [32-34] and nimotuzumabSpyTag/SpyCatcher-IRDye800CW and anti-MBP-SpyTag/ SpyCatcher-IRDye800CW cleared through the liver with fluorescence intensity peaking at early time points and gradually clearing up to $168 \mathrm{hpi}$ (Fig. 2). There was no significant difference between the liver uptake of nimotuzumab-SpyTag/SpyCatcher-IRDye800CW and antiMBP-SpyTag/SpyCatcher-IRDye800CW ( $p$ value $>0.05$ ) (see ESM Fig. S2). This agrees with data for the nonspecifically IRDye $800 \mathrm{CW}$-labeled nimotuzumab reported previously [31].

\section{Purification and Analysis of Diabody-SpyCatcher Fusion}

We converted an anti-HER3 antigen-binding fragment (Fab) [28] into a diabody with a C-terminus SpyCatcher fusion. This allowed us to assess the ligation efficiency in a different orientation than the antibody as well as the effect of site specifically labeling on a smaller antibodybased MTI probe. We constructed an anti-MBP-diabody as a control. Expression yields of the anti-HER3 diabody with or without SpyCatcher fusion were similar at $4 \pm 1.0 \mathrm{mg} / \mathrm{L}$ of bacterial culture. We analyzed the MW and purity of the diabody-SpyCatcher fusions (Fig. 3a). The anti-HER3 diabody-SpyCatcher and the anti-MBP diabodySpyCatcher migrated at approximately $40 \mathrm{kDa}$ on a reducing SDS-PAGE (Fig. 3a) and were 87 and $76 \%$ pure, respectively (Fig. 3a). The diabody is held together by non-covalent bonds between two fragments. The molecular weight of each anti-HER3 diabody fragment is $25 \mathrm{kDa}$ plus the $15 \mathrm{kDa}$ SpyCatcher, resulting in a $40 \mathrm{kDa}$ fusion protein. The $K_{\mathrm{D}}$ of anti-HER3 diabody-SpyCatcher was $24.2 \mathrm{nM}$ (Fig. 3a; Table 1), which was similar to the anti-HER3 diabody (24.3 nM) (Table 1).

\section{Site-Specific Labeling of Diabody-SpyCatcher Using the IRDye800CW-SpyTag}

We labeled anti-HER3 and anti-MBP diabody-SpyCatchers with fluorescent SpyTag using the scheme in Fig. 3b. We labeled the SpyTag peptide (AHIVMVDAYKPTK), which has two free lysines, with IRDye800CW-NHS (Fig. 3b). The SpyTag was labeled with 3-fold molar excess of IRDye 800CW-NHS in PBS, pH 7.4. We observed strong fluorescence for the SpyTag-IRDye800CW and a low level of coomassie blue staining on SDS-PAGE (Fig. 3c). We ligated the IRDye800CW-SpyTag with diabody-SpyCatcher (Fig. 3b) at a molar ratio of 3:1. The SpyTag-IRDye $800 \mathrm{CW}$ labeled diabody-SpyCatcher conjugates were fluorescent on an SDSPAGE (Fig. 3c). We calculated the number of IRDye $800 \mathrm{CW}$ molecules per labeled anti-HER3 and anti-MBP diabodySpyCatchers to be 2.76 and 2.44, respectively (Table 2). The diabody-SpyCatcher labeling was higher than the antibody- 
a

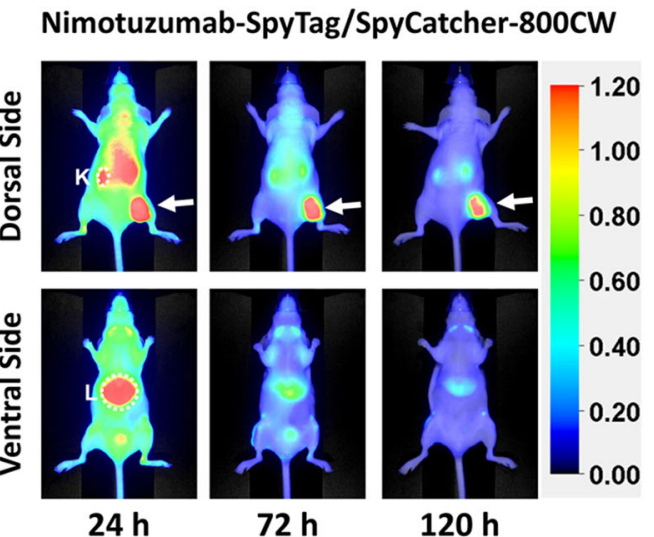

b

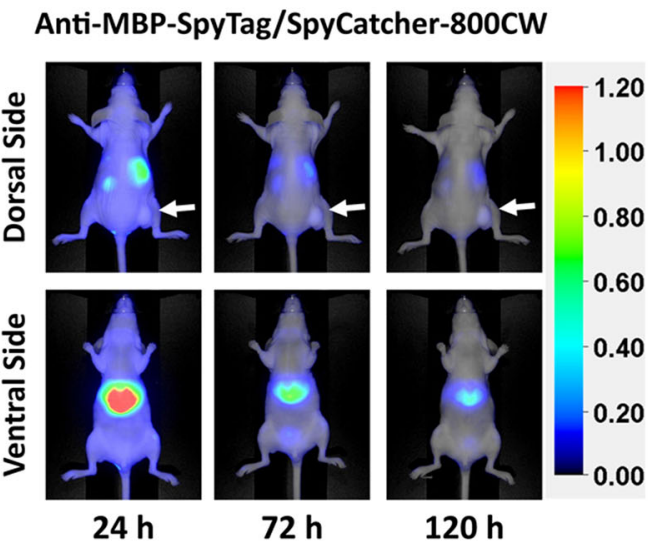

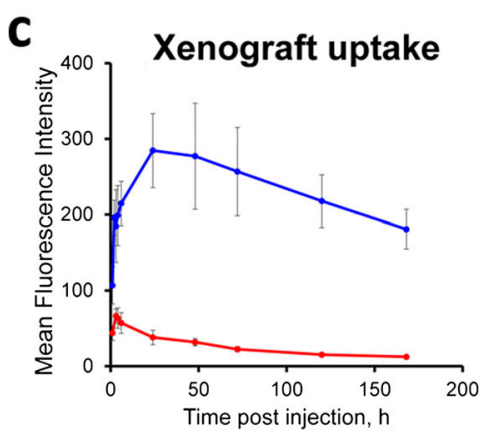
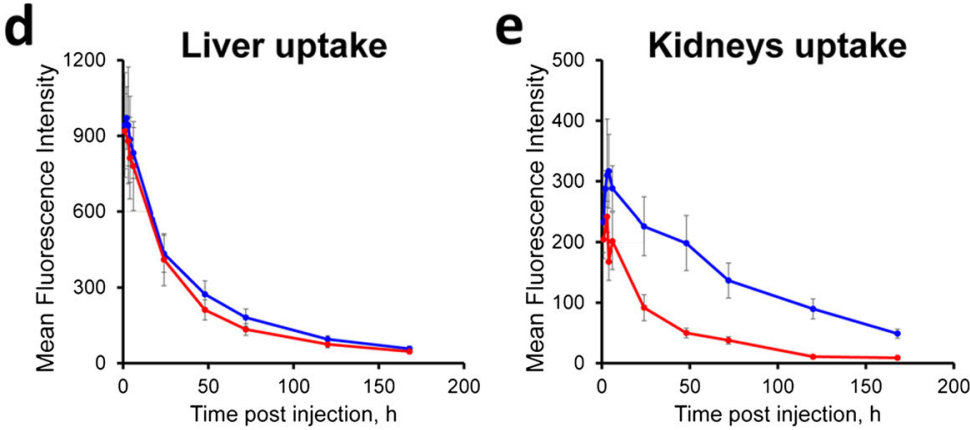

Nimotuzumab-SpyTag/SpyCatcher-800CW

Anti-MBP-SpyTag/SpyCatcher-800CW

Fig. 2. Near infrared imaging of the EGFR-positive murine xenograft using nimotuzumab-SpyTag/SpyCatcher-IRDye800CW. Representative near-infrared (NIR), dorsal (top), and ventral (bottom) images merged with white light images of CD-1 nude mice bearing subcutaneous A431 xenografts (right hind flank) at 24, 72, and $120 \mathrm{~h}$ post-intravenous injection with $0.5 \mathrm{nmol}$ of a nimotuzumab-SpyTag/SpyCatcher-IRDye800CW or b control anti-MBP-SpyTag/SpyCatcher-IRDye800CW. Xenografts are indicated with white arrows. Kidney $(\mathrm{K})$ and liver $(\mathrm{L})$ sites are indicated with dotted ovals. Biodistribution analysis of nimotuzumab-SpyTag/SpyCatcher-IRDye800CW and control anti-MBP-SpyTag/SpyCatcher-IRDye800CW calculated from regions of interest (ROI) for $\mathbf{c}$ xenografts, $\mathbf{d}$ the liver, and e the kidneys. Mean fluorescent signal (arbitrary units) for nimotuzumab-SpyTag/SpyCatcher-IRDye800CW (blue lines) and control anti-MBP-SpyTag/SpyCatcher-IRDye800CW (Orange lines) in A431 xenografts, the liver, and kidney are presented. Data are the average from three mice, and error bars represent standard deviation.

SpyTag labeling, likely due to the presence of two lysines on the SpyTag. The MW of the anti-HER3 SpyCatcher/SpyTagIRDye $800 \mathrm{CW}$ and the anti-MBP SpyCatcher/SpyTagIRDye $800 \mathrm{CW}$ diabodies were $\sim 45 \mathrm{kDa}$ (Fig. 3c, Table 2). The purity of the anti-HER3-SpyCatcher/SpyTagIRDye $800 \mathrm{CW}$ and the anti-MBP-SpyCatcher/SpyTagIRDye $800 \mathrm{CW}$ diabodies were 87 and $76 \%$, respectively (Fig. 3d, Table 2). The $K_{\mathrm{D}}$ of the anti-HER3-SpyCatcher/ SpyTag-IRDye800CW diabody was slightly lower (<2-fold) then the anti-HER3-SpyCatcher (Table 1). The anti-HER3SpyCatcher/SpyTag-IRDye800CW bound HER3-positive cell line, $\mathrm{FaDu}$ (Fig. 3e).
Near Infrared Fluorescent Imaging of Anti-HER3 Diabody-SpyTag/SpyCatcher-IRDye800CW

The in vivo distribution of the anti-HER3 diabody-SpyTag/ SpyCatcher-IRDye800CW was evaluated by injecting 0.5 nmole in mice bearing subcutaneous HER3-positive $\mathrm{FaDu}$ xenografts on their right hind limb. An anti-MBP diabody-SpyTag/SpyCatcher-IRDye $800 \mathrm{CW}$ was used as control. Mice were imaged at 1, 2, 3, 4, 6, 24, 48, and $72 \mathrm{hpi}$, and fluorescent intensity in the xenograft, liver, and kidneys were quantified. As early as $1 \mathrm{hpi}$, xenograft fluorescence was detected for the anti-HER3 diabody- 
a

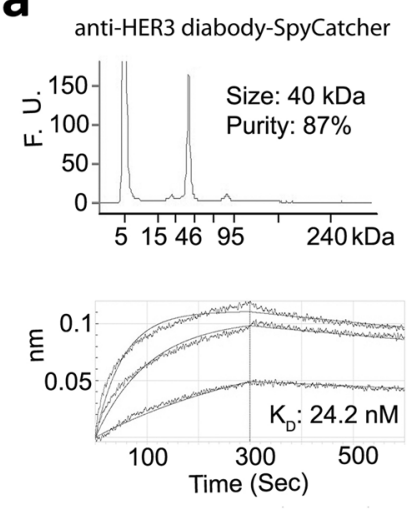

b

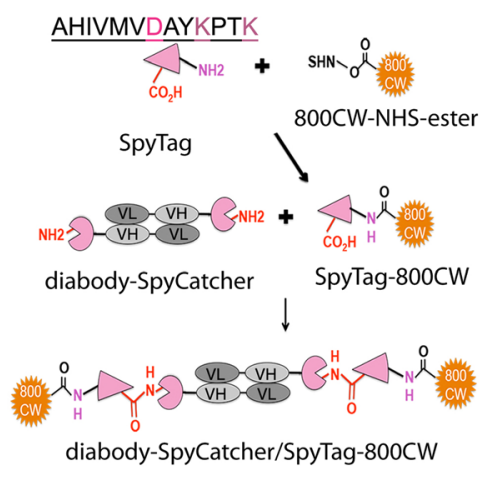

C

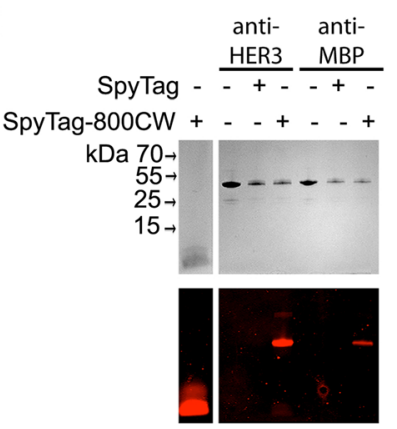

d
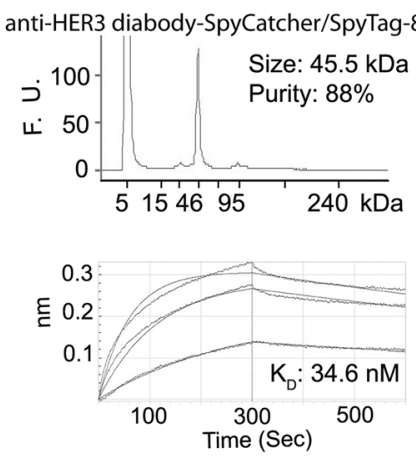

e

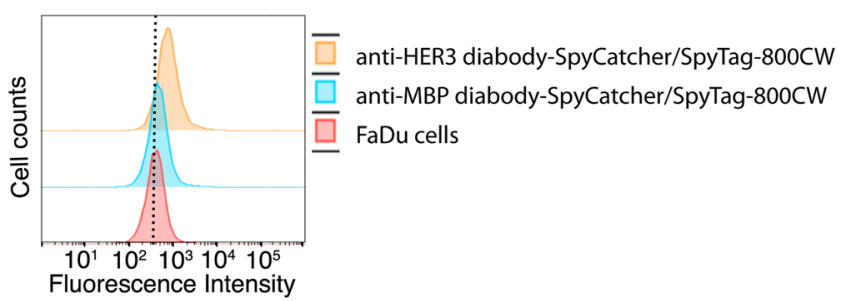

Fig. 3. Purification, site-specific labeling, and in vitro characterization of anti-HER3-diabody-SpyCatcher. a Bioanalyzer electropherograms (top) and biolayer interferometry kinetic analysis (bottom) of anti-HER3 diabody-SpyCatcher showing the purity, molecular weight $(\mathrm{MW})$, and dissociation constant $\left(K_{\mathrm{D}}\right)$ before site-specific labeling. Bioanalyzer was performed under reducing conditions. $5 \mathrm{kDa}$ peak is an internal standard used to align electropherograms. $K_{\mathrm{D}}$ was determined using biolayer interferometry with surface-immobilized HER3. b Site-specific labeling of anti-HER3-diabody-SpyCatcher with IRDye800CWNHS labeled SpyTag peptide. First, SpyTag was conjugated with IRDye800CW-NHS. IRDye800CW-NHS dye bearing an NHS ester reactive group was used to couple the primary amines containing lysines of SpyTag. Then IRDye800CW-NHS esterlabeled SpyTag was conjugated with anti-HER3-diabody-SpyCatcher for site-specific labeling. c Analysis of Protein L purified diabody-SpyCatcher using reducing SDS-PAGE (top). LI-COR-Odyssey infrared image of the same gel (bottom) showing only labeled antibody fragments. Anti-HER3-diabody-SpyCatcher and anti-MBP-diabody-SpyCatcher were conjugated with nonlabeled SpyTag or with previously labeled SpyTag-IRDye800CW. d Bioanalyzer electropherograms (top, $5 \mathrm{kDa}$ peak is an internal standard used to align electropherograms) and biolayer interferometry kinetic analysis (bottom) of anti-HER3-diabodySpyCatcher showing the purity, molecular weight (MW), and $K_{\mathrm{D}}$ after site-specific labeling. e. Flow cytometry analysis of binding of anti-HER3 diabody-SpyCatcher/SpyTag-IRDye800CW to FaDu cells.

SpyCatcher/SpyTag-IRDye800CW. Fast clearance of background fluorescence allowed better visualization of the xenograft at 4 hpi (Fig. 4a, c) relative to the larger nimotuzumab-SpyCatcher/SpyTag-IRDye $800 \mathrm{CW}$ with the A431 xenograft. By $24 \mathrm{hpi}$, the signal was diminished in the xenograft. The anti-MBP diabody-SpyCatcher/SpyTagIRDye $800 \mathrm{CW}$ showed little accumulation in the xenograft. The anti-HER3 diabody-SpyCatcher/SpyTag-IRDye800CW had 4.2-, 2.6-, and 1.9-fold more fluorescence in the xenograft than anti-MBP diabody-SpyCatcher/SpyTagIRDye $800 \mathrm{CW}$ at 1,4 , and $24 \mathrm{hpi}$, respectively, with significant differences $(p<0.01)$ between anti-HER3 and anti-MBP at all time points except 72 hpi (see ESM Fig. S3).

Medium-sized fragments (100 kDa) such as anti-CD105 $\mathrm{F}(\mathrm{ab}$ ')2 have been shown to clear through both renal and hepatic pathways [35]. Since we have increased the diabody size from $50 \mathrm{kDa}$ to roughly $90 \mathrm{kDa}$ through the addition of a SpyTag/SpyCatcher, we expected a similar clearance profile. There was a high fluorescence signal detected in both kidneys and liver injected with either the anti-HER3 or anti-MBP diabody-SpyCatcher/SpyTag-IRDye800CW that steadily decreased (Fig. 4). 
a

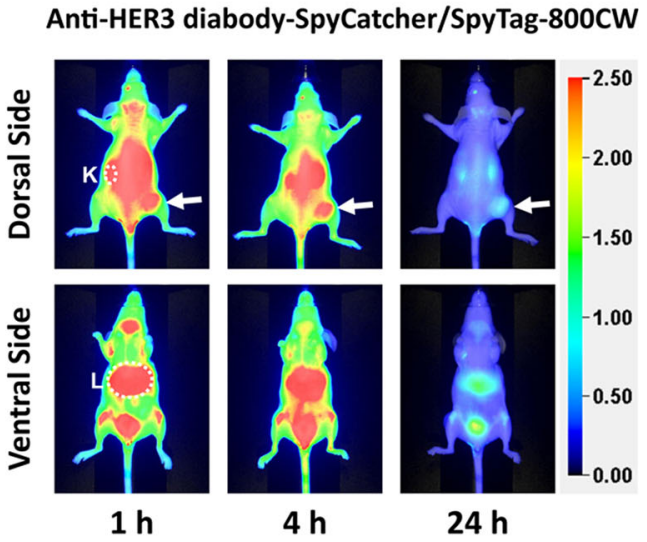

b

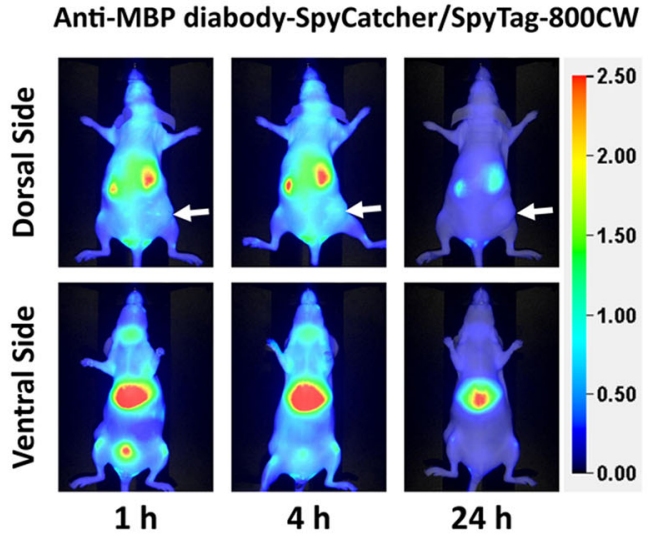

e

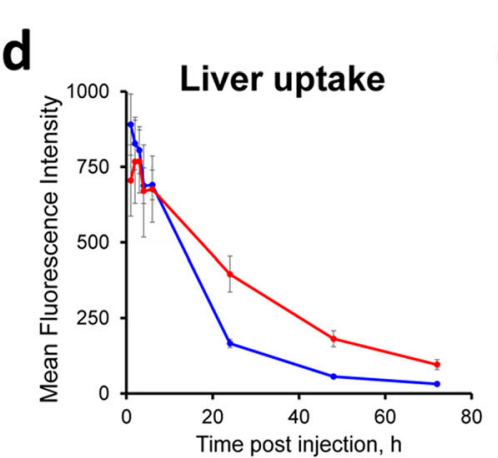

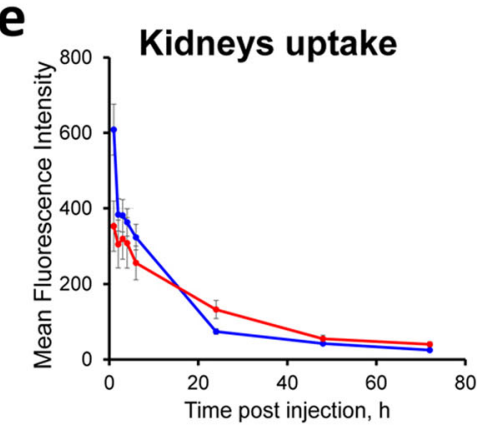

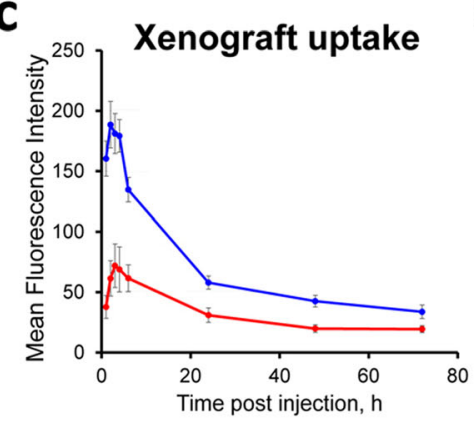

Fig. 4. Near infrared imaging of the HER3-positive murine xenograft using anti-HER3 diabody-SpyCatcher/SpyTagIRDye800CW. a, b Representative near-infrared (NIR), dorsal (top), and ventral (bottom) images merged with white light images of CD-1 nude mice bearing subcutaneous FaDu xenografts (right hind flank) at 24, 72, and $120 \mathrm{hpi} \mathrm{with} 0.5 \mathrm{nmol}$ of antiHER3 diabody-SpyCatcher/SpyTag-IRDye800CW (a) or control anti-MBP diabody-SpyCatcher/SpyTag-IRDye800CW (b). Xenografts are indicated with white arrows. Kidney $(\mathrm{K})$ and liver $(\mathrm{L})$ sites are indicated with dashed ovals. c. Biodistribution analysis of anti-HER3 diabody-SpyCatcher/SpyTag-IRDye800CW and control anti-MBP diabody-SpyCatcher/SpyTagIRDye800CW calculated from regions of interest (ROI) for xenografts, the liver, and kidneys. Mean fluorescent signal (arbitrary units) for anti-HER3 diabody-SpyCatcher/SpyTag-IRDye800CW (blue lines) and control anti-MBP diabody-SpyCatcher/ SpyTag-IRDye800CW (orange lines) in FaDu xenografts, the liver, and kidney are presented. Data are the average from three mice and error bars represent standard deviation.

\section{Biodistribution of IRDye800CW-Labeled SpyTag and SpyCatcher}

We imaged A431 xenografts with SpyCatcherIRDye $800 \mathrm{CW}$ or SpyTag-IRDye800CW as controls to confirm that the xenograft fluorescence was not due to SpyCatcher-IRDye $800 \mathrm{CW}$ or SpyTag-IRDye $800 \mathrm{CW}$ produced as a result of cleavage or degradation in vivo (Fig. 5). The SpyTag-IRDye800CW was cleared very rapidly and predominantly accumulated in the bladder by $4 \mathrm{hpi}$ with little accumulation in the xenograft. The SpyCatcherIRDye $800 \mathrm{CW}$ had dramatically different biodistribution than nimotuzumab-SpyTag/SpyCatcher-IRDye $800 \mathrm{CW}$ or the anti-MBP-SpyTag/SpyCatcher-IRDye $800 \mathrm{CW}$. The SpyCatcher-IRDye800CW showed very little xenograft uptake and was primarily cleared through the kidneys and liver with little accumulation in the xenograft (Fig. 5).

\section{Discussion}

Previously, it has been shown that site-specifically labeled immunoconjugates exhibit superior in vivo behavior compared to non-specifically labeled antibodies [36]. The SpyTag/SpyCatcher system is a robust and simple method for site-specific labeling antibodies or antibody fragments. The most common method for labeling antibodies involves the non-specific coupling of amine-reactive bifunctional probes to the primary amine on lysines, resulting in a heterogeneous probe with suboptimal pharmacological properties. We showed that antibodies and antibody fragments could be site-specifically labeled using the SpyTag/ SpyCatcher system without compromising antigen affinity. Nimotuzumab and the anti-HER3 diabody have lysines in their complementarity determining regions (CDRs) and decreases in affinity have been observed with antibodies 
a

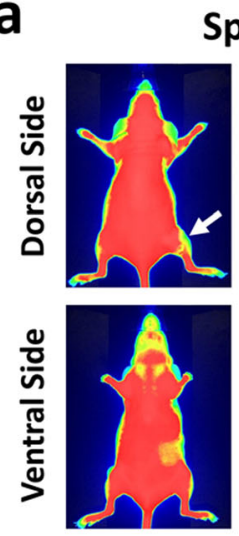

$1 \mathrm{~h}$
Spytag-IRDye800CW

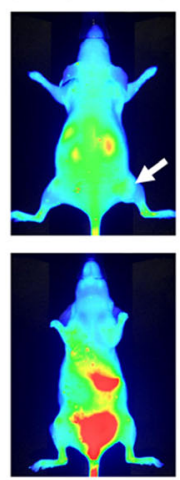

$4 \mathrm{~h}$

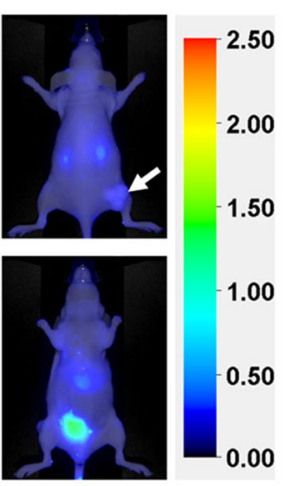

$24 \mathrm{~h}$ b

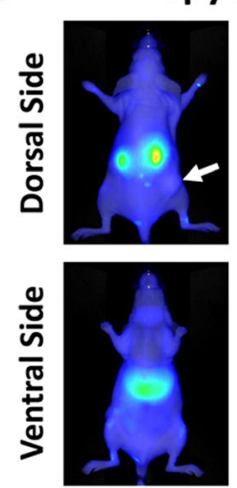

$24 \mathrm{~h}$
SpyCatcher-IRDye800CW
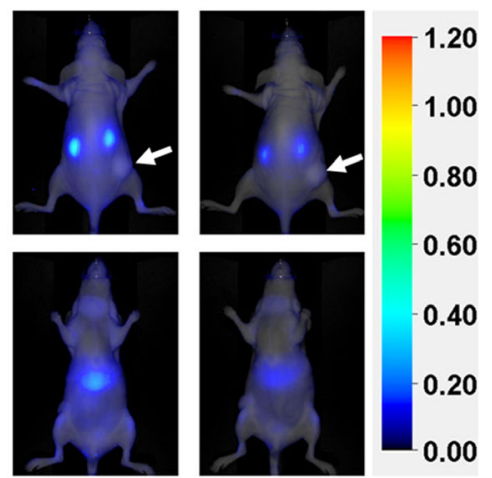

$120 \mathrm{~h}$

Fig. 5. Near infrared imaging of SpyTag-IRDye800CW and SpyCatcher-IRDye800CW. Representative near-infrared (NIR), dorsal (top), and ventral (bottom) images merged with white light images of CD-1 nude mice bearing subcutaneous xenografts (right hind flank). a SpyTag-IRDye800CW at 1, 4, and 24 hpi injection. b SpyCatcher-IRDye800CW at 24, 72, and 120 hpi. Xenografts are indicated with white arrows. Data are the representative of images from three mice.

containing lysines in their CDRs that are non-specifically labeled with IRDye800CW-NHS [3], highlighting the advantage of labeling these types of antibodies with sitespecific methods.

Although the SpyTag/SpyCatcher system relies on genetic manipulation and protein production, the irreversible covalent interaction between SpyTag and SpyCatcher fused proteins is highly specific and modular [17-22], which makes it useful for synthesizing multiple probes for in vivo imaging. This SpyTag or SpyCatcher can be fused to either terminus of an antibody or an antibody fragment, which can then be produced in bulk and can be labeled with any desired reporter, making it useful when repeated use of large amounts of antibodies are required [37]. The SpyTag/ SpyCatcher system is smaller than the commonly used peptide-based labeling systems such as SNAP-tag (181 a.a), CLIP-tag (181 a.a), and Halo-tag (220 a.a), and these labeling methods rely on synthetic probes for antibody labeling. A common method to site-specifically label diabodies involves adding a C-terminal cysteine. This cysteine is used to conjugate reporters with a reactive multimode [38, 39]. The SpyTag/SpyCatcher system does not require reducing agents during the labeling reaction as in case of cysteine-maleimide conjugation. Thus, disulfide bonds present in the antibodies remain oxidized during labeling, and the need for removing the reducing agent postconjugation is eliminated [40]. Additionally, the SpyCatcher/SpyTag reaction takes place at room temperature in the same buffer in which the antibody was purified, and there was no need to change buffers or $\mathrm{pH}$. Labeling the SpyTag or SpyCatcher prior to conjugation allows repetitive labeling of different batches of antibody or different antibodies with the same batch of labeled SpyTag or SpyCatcher. The SpyTag/SpyCatcher can be placed at any site within the antibody [17, 41] without compromising expression yield and binding properties. In addition, this system provides control over the labeling ratio of antibodies and fragments by either modulating the labeling ratio of the SpyTag or SpyCatcher or by "doping" in unlabeled SpyTag or SpyCatcher into the ligation reaction.

The addition of the SpyCatcher, a $15 \mathrm{kDa}$ protein, to an antibody may result in an immune response. Full-length SpyCatcher has been shown to elicit an immune response in mice [19]. To reduce this, $\mathrm{Li}$ et al. [16] developed an Nterminal-truncated SpyCatcher that dramatically reduces the immune response [19]. Further, the amount of antibody required for molecular imaging is generally far lower than that of therapeutic requirements [42] reducing the chance for an immunogenic reaction. Fierer et al. [43] and Siegmund et al. [20] engineered the SpyTag/SpyCatcher system to ligate two peptides, SpyTag, and Ktag using a SpyLigase enzyme. This system provides another avenue to eliminate the immune response as the SpyCatcher is removed from the ligated product. The SpyLigase system has been used to label antibodies with drug conjugates [20]. The ligation efficiency of the SpyLigase system is significantly lower than that of SpyTag/SpyCatcher system.

\section{Conclusions}

In conclusion, the SpyTag/SpyCatcher protein ligase provides a simple robust ligation system for labeling antibodies and antibody fragments. The modular nature of this approach allows rapid labeling of multiple batches of antibodies or many different antibodies. This system will be useful for rapidly evaluating imaging probes in murine models of disease. In addition to optical probes, the SpyTag/ SpyCatcher systems should also have applications with other imaging modalities and in constructing antibody drug conjugates. 
Acknowledgements. We thank the members of the Dr. Geyer and the Dr. Fonge Laboratories for critical review of this manuscript and sharing their experiences. We thank Carolina Gonzalez for technical contributions.

Author Contributions. MKA designed and performed the experiments and analyzed the data. AE designed and performed the experiments and analyzed the data. KB designed and supervised the experiments, and analyzed the data. WB performed the experiments. MKA and AE wrote the manuscript. KB reviewed and edited the manuscript. HF edited the manuscript and supervised the study. CRG supervised the study and wrote and edited the manuscript.

Funding. Canadian Cancer Society Research Institute Innovation Grant 705323, Western Diversification Canada 12939.

\section{Compliance with Ethical Standards}

\section{Conflict of Interest}

The authors declare that they have no conflict of interest.

Open Access This article is distributed under the terms of the Creative Commons Attribution 4.0 International License (http:// creativecommons.org/licenses/by/4.0/), which permits unrestricted use, distribution, and reproduction in any medium, provided you give appropriate credit to the original author(s) and the source, provide a link to the Creative Commons license, and indicate if changes were made.

\section{References}

1. Wu AM, Olafsen T (2015) Antibodies for molecular imaging of cancer. Cancer J 14:191-197

2. van Dongen GAMS, Visser GWM, Lub-de Hooge MN, de Vries EG, Perk LR (2007) Immuno-PET: a navigator in monoclonal antibody development and applications. Oncologist 12:1379-1389

3. Kijanka M, Warnders FJ, El Khattabi M et al (2013) Rapid optical imaging of human breast tumour xenografts using anti-HER2 VHHs site-directly conjugated to IRDye $800 \mathrm{CW}$ for image-guided surgery. Eur J Nucl Med Mol Imaging 40:1718-1729

4. Olafsen T, Wu AM (2010) Antibody vectors for imaging. Semin Nucl Med 40:167-181

5. Holliger P, Hudson PJ (2005) Engineered antibody fragments and the rise of single domains. Nat Biotechnol 23:1126-1136

6. Adumeau P, Sharma SK, Brent C, Zeglis BM (2016) Site-specifically labeled Immunoconjugates for molecular imaging - part 1: cysteine residues and glycans. Mol Imaging Biol 18:1-17

7. Adumeau P, Sharma SK, Brent C, Zeglis BM (2016) Site-specifically labeled immunoconjugates for molecular imaging - part 2: peptide tags and unnatural amino acids. Mol Imaging Biol 18:153-165

8. Hussain AF, Kampmeier F, Von Felbert V et al (2011) SNAP-tag technology mediates site specific conjugation of antibody fragments with a photosensitizer and improves target specific phototoxicity in tumor cells. Bioconjug Chem 22:2487-2495

9. Kampmeier F, Ribbert M, Nachreiner T, Dembski S, Beaufils F, Brecht A, Barth S (2009) Site-specific, covalent labeling of recombinant antibody fragments via fusion to an engineered version of 6-O-alkylguanine DNA alkyltransferase. Bioconjug Chem 20:1010-1015

10. Los GV, Encell LP, McDougall MG et al (2008) HaloTag: a novel protein labeling technology for cell imaging and protein analysis. ACS Chem Biol 3:373-382

11. Yin J, Liu F, Li X, Walsh CT (2004) Labeling proteins with small molecules by site-specific posttranslational modification. J Am Chem Soc 126:7754-7755

12. Massa S, Vikani N, Betti C, Ballet S, Vanderhaegen S, Steyaert J, Descamps B, Vanhove C, Bunschoten A, van Leeuwen FWB, Hernot S, Caveliers V, Lahoutte T, Muyldermans S, Xavier C, Devoogdt N (2016) Sortase A-mediated site-specific labeling of camelid singledomain antibody-fragments: a versatile strategy for multiple molecular imaging modalities. Contrast Media Mol Imaging 11:328-339
13. Dennler P, Chiotellis A, Fischer E et al (2014) Transglutaminasebased chemo-enzymatic conjugation approach yields homogeneous antibody-drug conjugates. Bioconjug Chem 25:569-578

14. Junutula JR, Bhakta S, Raab H, Ervin KE, Eigenbrot C, Vandlen R, Scheller RH, Lowman HB (2008) Rapid identification of reactive cysteine residues for site-specific labeling of antibody-Fabs. J Immunol Methods 332:41-52

15. Zakeri B, Fierer JO, Celik E, Chittock EC, Schwarz-Linek U, Moy VT, Howarth M (2012) Peptide tag forming a rapid covalent bond to a protein, through engineering a bacterial adhesin. Proc Natl Acad Sci 109:E690-E697

16. Li L, Fierer JO, Rapoport TA, Howarth M (2014) Structural analysis and optimization of the covalent association between SpyCatcher and a peptide tag. J Mol Biol 426:309-317

17. Alam MK, Gonzalez C, Hill W, el-Sayed A, Fonge H, Barreto K, Geyer CR (2017) Synthetic modular antibody construction by using the SpyTag/ SpyCatcher protein-ligase system. ChemBioChem 18:2217-2221

18. Brune $\mathrm{KD}$, Leneghan $\mathrm{DB}$, Brian IJ, Ishizuka AS, Bachmann MF, Draper SJ, Biswas S, Howarth M (2016) Plug-and-display: decoration of virus-like particles via isopeptide bonds for modular immunization. Sci Rep 6:19234

19. Liu Z, Zhou H, Wang W et al (2014) A novel method for synthetic vaccine construction based on protein assembly. Sci Rep 4:7266

20. Siegmund V, Piater B, Zakeri B, Eichhorn T, Fischer F, Deutsch C, Becker S, Toleikis L, Hock B, Betz UAK, Kolmar H (2016) Spontaneous Isopeptide bond formation as a powerful tool for engineering site-specific antibody-drug conjugates. Sci Rep 6:39291

21. Kasaraneni N, Chamoun-Emanuelli AM, Wright G, Chen Z (2017) Retargeting lentiviruses via spyCatcher-spyTag chemistry for gene delivery into specific cell types. MBio 8:e01860-e01817

22. Bedbrook CN, Kato M, Ravindra kumar S et al (2015) Genetically encoded spy peptide fusion system to detect plasma membranelocalized proteins in vivo. Chem Biol 22:1108-1121

23. Hynes NE, MacDonald G (2009) ErbB receptors and signaling pathways in cancer. Curr Opin Cell Biol 21:177-184

24. Chekol R, Bernhard W, Viswas RS et al (2017) ${ }^{89} \mathrm{Zr}$-nimotuzumab for potential clinical translation as an anti-EGFR immunoPET agent. $\mathrm{J}$ Nucl Med 58:688

25. Lee-Hoeflich ST, Crocker L, Yao E, Pham T, Munroe X, Hoeflich KP, Sliwkowski MX, Stern HM (2008) A central role for HER3 in HER2-amplified breast cancer: implications for targeted therapy. Cancer Res 68:5878-5887

26. Narayan M, Wilken JA, Harris LN, Baron AT, Kimbler KD, Maihle NJ (2009) Trastuzumab-induced HER reprogramming in "resistant" breast carcinoma cells. Cancer Res 69:2191-2194

27. Gibson DG, Young L, Chuang RY, Venter JC, Hutchison CA, Smith HO (2009) Enzymatic assembly of DNA molecules up to several hundred kilobases. Nat Methods 6:343-345

28. Vellalore Maruthachalam B, El-Sayed A, Liu J et al (2017) A singleframework synthetic antibody library containing a combination of canonical and variable complementarity determining regions. Chembiochem 18:2247-2259

29. Garner AP, Bialucha CU, Sprague ER, Garrett JT, Sheng Q, Li S, Sineshchekova O, Saxena P, Sutton CR, Chen D, Chen Y, Wang H, Liang J, Das R, Mosher R, Gu J, Huang A, Haubst N, Zehetmeier C, Haberl M, Elis W, Kunz C, Heidt AB, Herlihy K, Murtie J, Schuller A, Arteaga CL, Sellers WR, Ettenberg SA (2013) An antibody that locks HER3 in the inactive conformation inhibits tumor growth driven by HER2 or neuregulin. Cancer Res 73:6024-6035

30. Persson H, Ye W, Wernimont A, Adams JJ, Koide A, Koide S, Lam R, Sidhu SS (2013) CDR-H3 diversity is not required for antigen recognition by synthetic antibodies. J Mol Biol 425:803-811

31. Bernhard W, El-Sayed A, Barreto K et al (2018) Near infrared fluorescence imaging of EGFR expressionin vivousing IRDye800CW-nimotuzumab. Oncotarget 9:6213-6227

32. Voss SD, Smith SV, DiBartolo N, McIntosh LJ, Cyr EM, Bonab AA, Dearling JLJ, Carter EA, Fischman AJ, Treves ST, Gillies SD, Sargeson AM, Huston JS, Packard AB (2007) Positron emission tomography (PET) imaging of neuroblastoma and melanoma with ${ }^{64} \mathrm{Cu}-\mathrm{SarAr}$ immunoconjugates. Proc Natl Acad Sci U S A 104:17489-17493

33. Paudyal B, Paudyal P, Oriuchi N, Hanaoka H, Tominaga H, Endo K (2011) Positron emission tomography imaging and biodistribution of 
vascular endothelial growth factor with ${ }^{64} \mathrm{Cu}$-labeled bevacizumab in colorectal cancer xenografts. Cancer Sci 102:117-121

34. Paudyal P, Paudyal B, Iida Y, Oriuchi N, Hanaoka H, Tominaga H, Ishikita T, Yoshioka H, Higuchi T, Endo K (2009) Dual functional molecular imaging probe targeting CD20 with PET and optical imaging. Oncol Rep 22:115-119

35. Hong H, Zhang Y, Orbay $\mathrm{H}$ et al (2013) Positron emission tomography imaging of tumor angiogenesis with a $61 / 64 \mathrm{Cu}$-labeled $\mathrm{F}\left(\mathrm{ab}^{\prime}\right) 2$ antibody fragment. Mol Pharm 10:709-716

36. Okeley NM, Toki BE, Zhang X, Jeffrey SC, Burke PJ, Alley SC, Senter PD (2013) Metabolic engineering of monoclonal antibody carbohydrates for antibody-drug conjugation. Bioconjug Chem 24:1650-1655

37. Yang B, Treweek JB, Kulkarni RP, Deverman BE, Chen CK, Lubeck E, Shah S, Cai L, Gradinaru V (2014) Single-cell phenotyping within transparent intact tissue through whole-body clearing. Cell 158:945-958

38. Sirk SJ, Olafsen T, Barat B, Bauer KB, Wu AM (2008) Sitespecific, thiol-mediated conjugation of fluorescent probes to cysteine-modified diabodies targeting CD20 or HER2. Bioconjug Chem 19:2527-2534

39. Olafsen T, Cheung CW, Yazaki PJ, Li L, Sundaresan G, Gambhir SS, Sherman MA, Williams LE, Shively JE, Raubitschek AA, Wu AM (2004) Covalent disulfide-linked anti-CEA diabody allows sitespecific conjugation and radiolabeling for tumor targeting applications. Protein Eng Des Sel 17:21-27

40. Behrens CR, Liu B (2014) Methods for site-specific drug conjugation to antibodies. MAbs 6:46-53

41. Yumura K, Akiba H, Nagatoishi S, Kusano-Arai O, Iwanari H, Hamakubo T, Tsumoto K (2017) Use of SpyTag/SpyCatcher to construct bispecific antibodies that target two epitopes of a single antigen. J Biochem 162:203-210

42. Chames P, Van Regenmortel M, Weiss E, Baty D (2009) Therapeutic antibodies: successes, limitations and hopes for the future. $\mathrm{Br} \mathrm{J}$ Pharmacol 157:220-233

43. Fierer JO, Veggiani G, Howarth M (2014) SpyLigase peptide-peptide ligation polymerizes affibodies to enhance magnetic cancer cell capture. Proc Natl Acad Sci 111:E1176-E1181 